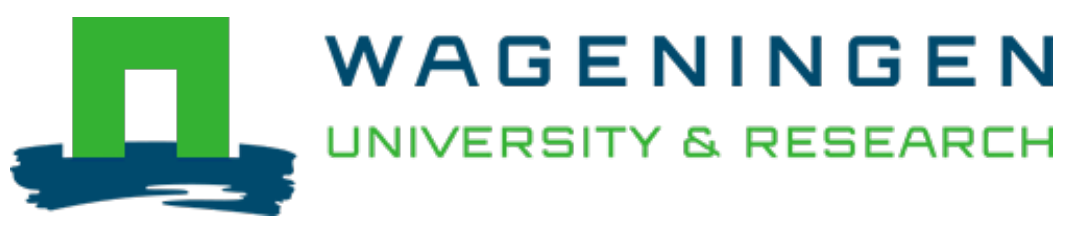

\title{
Monitoring habitat types by the mixed multinomial logit model using panel data
}

Ecological Indicators

Brus, D.J.; Slim, P.A.; Gort, G.; Heidema, A.H.; Dobben, H.F.

https://doi.org/10.1016/j.ecolind.2016.02.043

This article is made publicly available in the institutional repository of Wageningen University and Research, under the terms of article $25 \mathrm{fa}$ of the Dutch Copyright Act, also known as the Amendment Taverne. This has been done with explicit consent by the author.

Article $25 \mathrm{fa}$ states that the author of a short scientific work funded either wholly or partially by Dutch public funds is entitled to make that work publicly available for no consideration following a reasonable period of time after the work was first published, provided that clear reference is made to the source of the first publication of the work.

This publication is distributed under The Association of Universities in the Netherlands (VSNU) 'Article $25 \mathrm{fa}$

implementation' project. In this project research outputs of researchers employed by Dutch Universities that comply with the legal requirements of Article $25 \mathrm{fa}$ of the Dutch Copyright Act are distributed online and free of cost or other barriers in institutional repositories. Research outputs are distributed six months after their first online publication in the original published version and with proper attribution to the source of the original publication.

You are permitted to download and use the publication for personal purposes. All rights remain with the author(s) and / or copyright owner(s) of this work. Any use of the publication or parts of it other than authorised under article $25 \mathrm{fa}$ of the Dutch Copyright act is prohibited. Wageningen University \& Research and the author(s) of this publication shall not be held responsible or liable for any damages resulting from your (re)use of this publication.

For questions regarding the public availability of this article please contact openscience.library@,wur.nl 


\title{
Monitoring habitat types by the mixed multinomial logit model using panel data
}

\author{
D.J. Brus ${ }^{a, *}$, P.A. Slim ${ }^{a}$, G. Gort ${ }^{b}$, A.H. Heidema ${ }^{a}$, H. van Dobben ${ }^{a}$ \\ a Alterra, Wageningen University and Research Centre, PO Box 47, 6700 AA Wageningen, The Netherlands \\ ${ }^{\mathrm{b}}$ Mathematical and Statistical Methods Group, Wageningen University and Research Centre, PO Box 16, 6700 AC Wageningen, The Netherlands
}

\section{A R T I C L E I N F O}

\section{Article history:}

Received 28 October 2015

Received in revised form 4 February 2016

Accepted 16 February 2016

Available online 25 April 2016

\section{Keywords:}

Habitats Directive

Mapping

Sampling design

Random coefficient model

Multinomial logistic regression

\begin{abstract}
A B S T R A C T
Habitats in the Wadden Sea, a world heritage area, are affected by land subsidence resulting from natural gas extraction and by sea level rise. Here we describe a method to monitor changes in habitat types by producing sequential maps based on point information followed by mapping using a multinomial logit regression model with abiotic variables of which maps are available as predictors.

In a 70 ha study area a total of 904 vegetation samples has been collected in seven sampling rounds with an interval of 2-3 years. Half of the vegetation plots was permanent, violating the assumption of independent data in multinomial logistic regression. This paper shows how this dependency can be accounted for by adding a random effect to the multinomial logit (MLN) model, thus becoming a mixed multinomial logit (MMNL) model. In principle all regression coefficients can be taken as random, but in this study only the intercepts are treated as location-specific random variables (random intercepts model). With six habitat types we have five intercepts, so that the number of extra model parameters becomes 15,5 variances and 10 covariances.

The likelihood ratio test showed that the MMNL model fitted significantly better than the MNL model with the same fixed effects. McFadden- $R^{2}$ for the MMNL model was 0.467, versus 0.395 for the MNL model. The estimated coefficients of the MMNL and MNL model were comparable; those of altitude, the most important predictor, differed most. The MMNL model accounts for pseudo-replication at the permanent plots, which explains the larger standard errors of the MMNL coefficients. The habitat type at a given location-year combination was predicted by the habitat type with the largest predicted probability. The series of maps shows local trends in habitat types most likely driven by sea-level rise, soil subsidence, and a restoration project.

We conclude that in environmental modeling of categorical variables using panel data, dependency of repeated observations at permanent plots should be accounted for. This will affect the estimated probabilities of the categories, and even stronger the standard errors of the regression coefficients.
\end{abstract}

(C) 2016 Elsevier Ltd. All rights reserved.

\section{Introduction}

In the northern part of The Netherlands natural gas is extracted at a depth of 3-4 km, causing land subsidence up to $40 \mathrm{~cm}$ at surface level. This land subsidence, together with sea level rise, may lead to changes in vegetation and habitats in the Wadden Sea, a UNESCO world heritage area and a European protected habitat reserve consisting of sand barrier islands, salt marshes and mudflats. To follow these changes a monitoring network was installed on the coastal

\footnotetext{
* Corresponding author. Tel.: +31317486520.

E-mail addresses: dick.brus@wur.nl (D.J. Brus), pieter.slim@wur.nl (P.A. Slim), gerrit.gort@wur.nl (G. Gort), nanny.heidema@wur.nl (A.H. Heidema), han.vandobben@wur.nl (H.van Dobben).
}

plain of the island of Ameland (The Netherlands). This network was designed such that the data can be used both for estimation of the spatial extent of habitat types and for mapping habitat types. (Note that in this paper we use the term habitat type in the sense of EC (2007); in practice, the habitat typology in coastal areas is a course vegetation typology.) In a previous paper we used these data to estimate time trends in the areal fractions of local vegetation types (Brus et al., 2014). The areal fractions at the sampling times were estimated by design-based estimation, i.e. the estimates are based on the inclusion densities of the sampling locations (Särndal et al., 1992).

This paper deals with the second aim of the monitoring network, the mapping of the habitat types. When there is a relation between the habitat types and environmental variables of which maps are available, such as terrain attributes derived from a digital elevation 
model, then a model describing this relation can be used to map the habitat types. The response variable of the model, the habitat types, is a categorical variable, and therefore a multinomial logit model is appropriate (Hosmer and Lemeshow, 1989). In this paper we show how such a model was used to map the habitat types at the seven sampling times (2001, 2004, 2006, 2008, 2010, 2012 and 2014). A complication is that half of the sampling locations is permanent. So, at these permanent plots repeated observations were collected which cannot be treated as independent data. A central research question of this paper is how this temporal dependency in the data collected at the permanent plots can be accounted for in fitting the multinomial logit model.

The relation between the habitat types and environmental variables is described by a so-called mixed multinomial logit model. Similar to a linear mixed model such model contains both fixed and random effects. Mixed multinomial logit models are widely used in econometrics to explain discrete choices made by individuals, such as choices between transport modes or brands of some product, see for instance Jain et al. (1994) and Revelt and Train (1998). When individuals choose multiple times and all choices are recorded, the data cannot be treated as independent. By substituting individuals by vegetation plots and the discrete choices by habitat types, the analogue becomes clear. Mixed multinomial logit models are not widely applied in ecological modeling, and publications on this topic are rare. An example of an ecological application is Duchesne et al. (2010), in which the probability that an animal selects a location in a specific habitat type is described by a mixed multinomial logit model.

Because of the very few ecological papers on this topic we will explain the theory of mixed multinomial logit modeling. The case study on the habitat data in the study area of Ameland describes how the theory was implemented. We will show that accounting for the dependency of the data at the permanent plots leads to somewhat different estimates of the regression coefficients and larger standard errors of these coefficients. As a consequence, also the predicted probabilities of the habitat types as obtained with the mixed multinomial logit model differed from those obtained with the multinomial logit model assuming independent data.

\section{Theory: the mixed multinomial logit model}

Suppose we have no repeated observations at permanent plots, just one observation per randomly selected plot. In this case the occurrence of habitat types can be modelled by a multinomial logit model (MNL). In such model the probability of occurrence of a habitat is related to environmental covariates, such as altitude, exposure et cetera. All probabilities should be larger than zero, and the sum of the probabilities over all habitat types should equal 1 . To achieve this, one habitat type is taken as a baseline category, and the $\log$ of the ratio of the probability of a habitat $j$ to the probability of a baseline habitat, referred to as a multinomial logit, is modelled as a linear combination of the environmental covariates (Hartzel et al., 2001):

$\log \left(\frac{p_{i j}}{p_{i 1}}\right)=\sum_{p=0}^{P} x_{i p} \beta_{p j}$

for $j=2 \cdots J$ ( $J$ is total number of observed habitat types), with $p_{i j}$ the probability of habitat $j$ at location $i, x_{i p}$ the value of environmental covariate (predictor) $p$ at location $i$ (with $x_{i 0}=1$ for the intercept), and $\beta_{p j}$ the regression coefficient associated with predictor $p$ for habitat type $j$, and $P$ the number of predictors. Note that the same set of environmental covariates is used for all habitat types, but that the regression coefficients differ between the habitat types. So, for instance, altitude can have a strong positive effect on one habitat type (if altitude increases with one unit, the probability of that habitat type increases strongly), but only a weak or even negative effect on another habitat type.

In the case study described hereafter at half of the locations we have repeated observations of habitat types. These are the permanent plots. In this case it is not realistic to assume that the repeated observations at a given permanent plot are independent. If we have observed habitat type $j$ at a location $i$ at time 1, then the probability of observing this habitat type again at subsequent times is relatively high, because spatial patterns of habitat types are quite persistent. To account for this dependency of the observations of the habitat types at the permanent plots, we relax the assumption that the regression coefficients for a given habitat type are the same for all

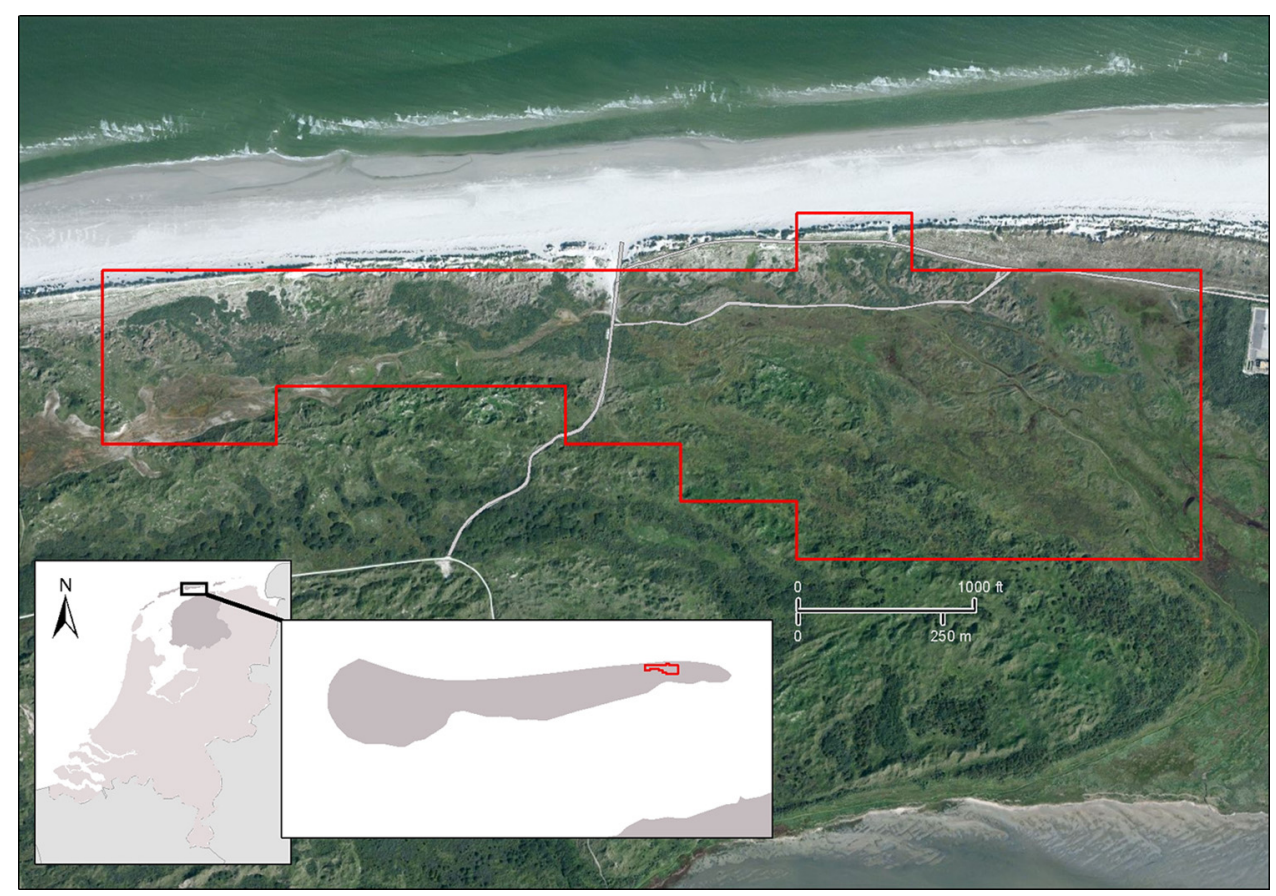

Fig. 1. Study area. 
locations. The idea is that, given the location-specific values of the regression coefficients, the repeated observations can be treated as independent data. However, it is unfeasible to estimate the regression coefficients for every location. A way out is to give each location it's own coefficients, but by restraining them in a specific way: they should behave like random draws from a normal distribution with mean zero and variance(s) to be estimated. In other words, we add random coefficients with zero means to the model of Eq. (1) (see e.g. Chen and Kuo, 2001; Hartzel et al., 2001; Hedeker, 2003; de Rooij and Schouteden, 2012). In the case study only random intercepts $u_{i j}$ are added; the regression coefficients of the environmental covariates are assumed constant throughout the area, so that the model becomes:

$\log \left(\frac{p_{i t j \mid \mathbf{u}_{i}}}{p_{i t 1 \mid \mathbf{u}_{i}}}\right)=\sum_{p=0}^{P} x_{i t p} \beta_{p j}+u_{i j}=\beta_{0 j}+u_{i j}+\sum_{p=1}^{P} x_{i t p} \beta_{p j}$

with $p_{i t j \mid \mathbf{u}_{i}}$ the probability of habitat $j$ at location $i$ and time $t$ conditional on the vector with random intercepts $\mathbf{u}_{i}=\left(u_{2 i}, \ldots, u_{J i}\right)$ at location $i$. In the resulting Mixed Multinomial Logit Model (MMNL) the repeated observations per location are no longer independent, but are allowed to be correlated because of the random intercepts. In the MMNL not only the regression coefficients need to be estimated, but also the variances of the random intercepts (for each of the $J-1$ logits), and their covariances. In the case study there are $J=6$ habitats, leading to 5 intercept variances and 10 covariances. Therefore, compared to the ordinary multinomial logit (MNL) model, 15 extra parameters needs to be estimated in the MMNL.

The model parameters (regression coefficients, variances and covariances of the random intercepts) are estimated by maximum likelihood. This means that those parameter values are searched for that maximize the probability of the observed habitats. This maximum likelihood estimation requires the unconditional probabilities of the habitats at the sampling locations. The unconditional probability $p_{i t j}$ equals the expected value of the conditional probability $p_{i t j \mid \mathbf{u}_{i}}$, where the expectation is computed with the joint probability density of the random coefficients. With $J=6$ habitats and random intercepts only, computation of this expectation already involves a five-dimensional integration, which is not feasible. Integration by simulation then offers an alternative approach (Train, 2003). This involves the drawing of a large number of intercepts from their joint distribution, computing the probabilities conditional on these randomly drawn intercepts, and finally computing the average of these conditional probabilities.

Once we have the unconditional probabilities of habitat $j$ at all observation times at a location $i$, the unconditional probability of habitat $j$ at location $i$ can be computed by multiplication (recall that, conditional on the random intercepts, the observations are assumed independent). In maximum likelihood estimation of the model parameters one unconditional probability per location is used.

\section{Case study}

\subsection{Study area}

The barrier island of Ameland $\left(53^{\circ} 28^{\prime} \mathrm{N}, 5^{\circ} 54^{\prime} \mathrm{E}\right)$ is situated along the coast of The Netherlands, separating the Wadden Sea from the North Sea. The study area of 70 ha is on the eastern part of Ameland, a natural area with little human influence (Fig. 1). In the study area a gradient is present from white dunes in the North to salt marshes in the South. Part of the study site is well above the present sea level, and part is flooded by seawater or brackish water a

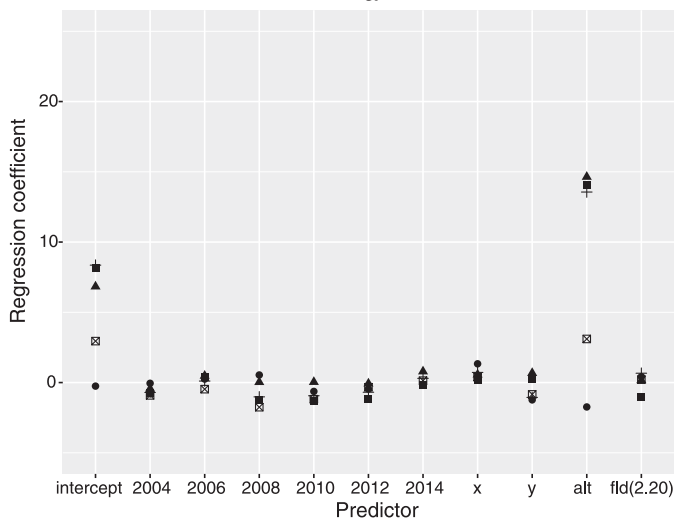

C

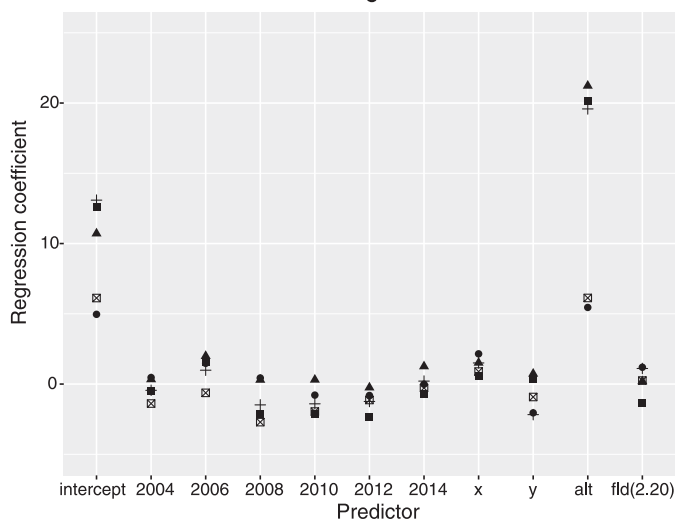

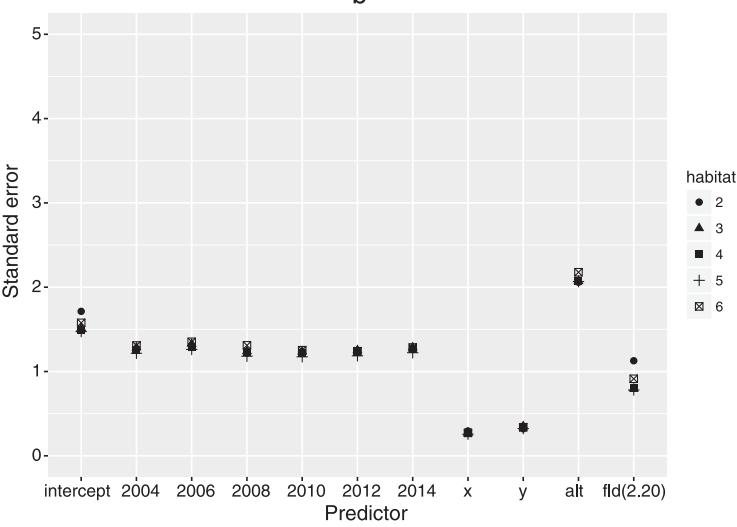

d

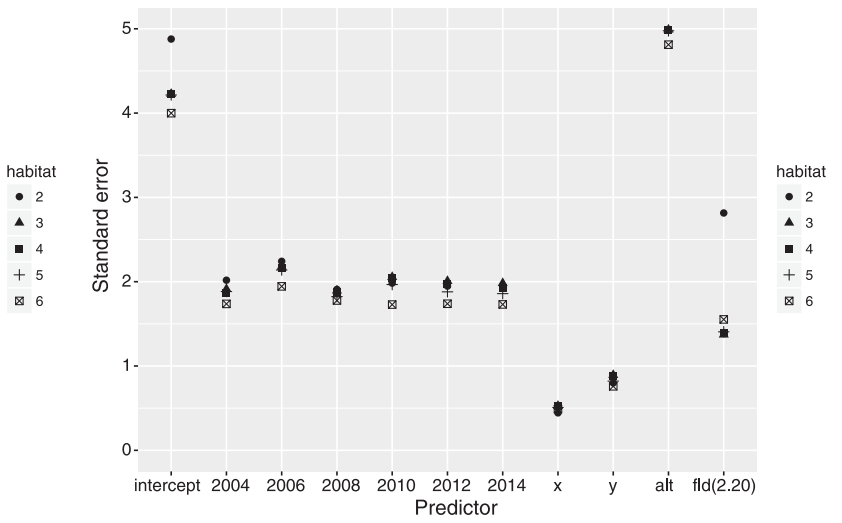

Fig. 2. Estimated regression coefficients and their standard errors for the MNL (a, b) and MMNL model (c, d). 
up to ca. 100 days per year. Gas extraction in this area started in 1985 (Brus et al., 2014).

\subsection{Design of monitoring network}

As a space-time design a supplemented panel design was chosen. This type of design is a compromise between a staticsynchronous design (also referred to as a pure panel), in which all plots are permanent, and an independent synchronous design, in which new plots are selected every sampling time, independent of the plots of previous sampling times (de Gruijter et al., 2006). A proportion of the plots is observed all seven sampling times 2001, 2004, 2006, 2008, 2010, 2012 and 2014 (the permanent plots) and the remaining plots only once (the changing plots). The proportion of permanent plots was 0.5. Brus et al. (2014) found that the precision of the estimated linear trend of the areal fractions of vegetation types as obtained with the supplemented panel design was only marginally lower than for a static-synchronous design.

For mapping the habitat types by a multinomial logit regression model we expect a supplemented panel to outperform a static-synchronous design. We must account for the repeated observations at the permanent plots. These repeated observations are not independent. If a given habitat type has been observed at a given sampling time, then the probability of observing the same habitat type at the next sampling time will be larger than the unconditional probability. In other words there is less information in the time-series of $r$ observations at a single permanent plot than in the single observations at $r$ changing plots.

All plots were selected by probability sampling, which is required for design-based estimation of the spatial extent of the habitat types (Cochran, 1977). The permanent plots were selected with a systematic unaligned random sampling design (SY) (Quenouille, 1949). The study area is first divided into square cells of $100 \mathrm{~m} \times 100 \mathrm{~m}$, and one plot is selected in each cell, although not independently. A random $x$-coordinate is generated for each row of cells, and a random $y$ coordinate for each column. The sampling plot in a cell is then found by combining the coordinates of its row and column. The resulting spatial pattern is irregular, but the locations are evenly spread over the study area.

The changing plots were selected according to a stratified simple random sampling design (ST) (de Gruijter et al., 2006; Lohr, 1999). The strata consisted of two neighbouring $100 \mathrm{~m} \times 100 \mathrm{~m}$ cells used in selecting the SY sample. The geographical spread of these plots is not as good as for the permanent plots, but still pretty good. The sample sizes of both samples, SY and ST, equals 70 plots per year, so that the total sample size was 140 plots per sampling time.

This supplemented panel design was not implemented perfectly. There are two distortions. First, in 2001 only permanent plots were selected (no ST sample), so that the total sample size in 2001 equaled 70 . Second, by accident in 2006 no new ST sample of plots was selected, but the ST sample of 2004 was revisited. As a consequence the samples of 2004 and 2006 have complete overlap instead of a $50 \%$ overlap.

The total number of unique plot-year combinations equals $70+6 \times 140=910$. At six of these space-time coordinates observations are missing because of bare sand without any plant species, so that the total number of observations equals 904 . The total number of unique plots equals 70 permanent plots $+5 \times 70$ changing plots which makes 420 plots.

\subsection{Vegetation data}

Each vegetation sampling unit consisted of a circular plot with a radius of $1.13 \mathrm{~m}$ (area of plot is $4 \mathrm{~m}^{2}$ ). Plots were localised in the field with RTK-GPS. Vegetation sampling was carried out in 2001 and at two-year intervals between 2004 and 2014. A vegetation sample a

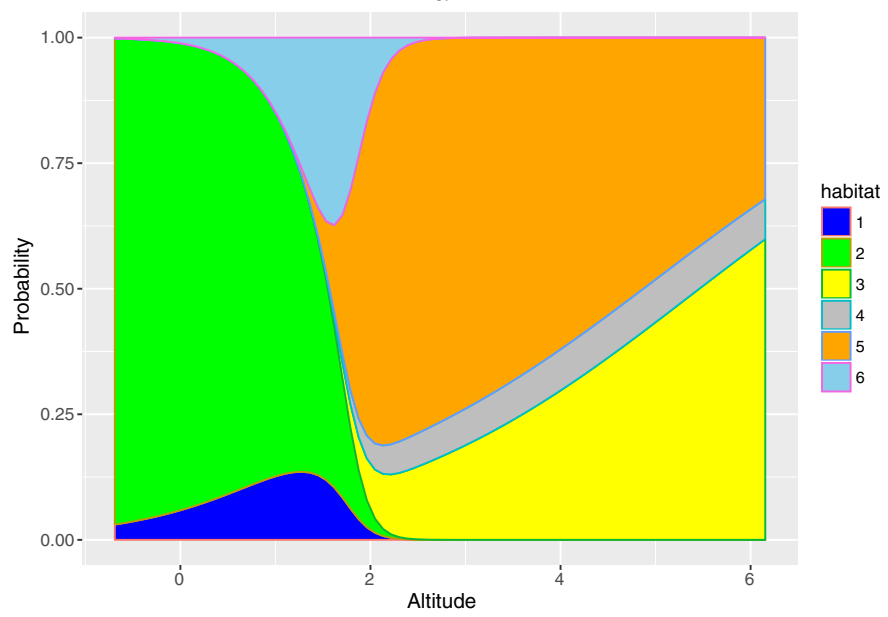

b

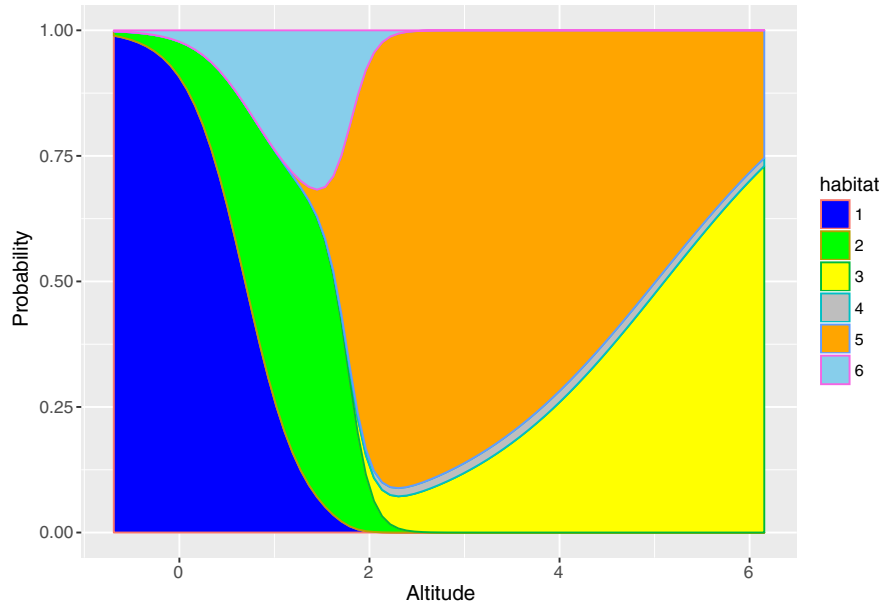

Fig. 3. Probabilities of the six habitat types as a function of altitude for the MNL (a) and MMNL model (b), for year 2014, flooded(2.20)=TRUE, and mean values for Easting and Northing.

consists of a list of phanerogamic and cryptogamic species found in the plot, together with their quantities estimated as cover fractions of their horizontal projections. Cover per species was visually estimated in a nine-point scale but back transformed to percentage before processing the data.

Each vegetation sample was assigned to a habitat type or a combination of habitat types in the sense of EC (2007), as follows. We used the program ASSOCIA (van Tongeren et al., 2008) to assign each sample to a vegetation type according to Schaminée et al. (1998). Next, we translated these vegetation types into (combinations of) habitat types using the translation table for The Netherlands given by van Dobben et al. (2014). This procedure yielded the following types (names and circumscriptions as in EC, 2007):

1. Salicornia and other annuals colonizing mud and sand.

2. Atlantic salt meadows (Glauco-Puccinellietalia maritimae).

3. Shifting dunes along the shoreline with Ammophila arenaria ('white dunes'), or Embryonic shifting dunes.

4. Fixed coastal dunes with herbaceous vegetation ('grey dunes').

5. Dunes with Hippophae rhamnoides.

6. Humid dune slacks.

Table 1 shows the yearly frequencies of the habitat types. 
Table 1

Sample frequencies of habitat types per year; for description of habitat types, see text.

\begin{tabular}{llllllll}
\hline & 2001 & 2004 & 2006 & 2008 & 2010 & 2012 & 2014 \\
\hline 1 & 0.014 & 0.029 & 0.022 & 0.058 & 0.058 & 0.050 & 0.029 \\
2 & 0.10 & 0.17 & 0.17 & 0.29 & 0.17 & 0.17 & 0.14 \\
3 & 0.12 & 0.14 & 0.14 & 0.22 & 0.24 & 0.19 & 0.19 \\
4 & 0.29 & 0.25 & 0.28 & 0.14 & 0.14 & 0.15 & 0.16 \\
5 & 0.42 & 0.37 & 0.35 & 0.27 & 0.33 & 0.34 & 0.39 \\
6 & 0.058 & 0.043 & 0.043 & 0.029 & 0.058 & 0.11 & 0.10 \\
\hline
\end{tabular}

\subsection{Candidate predictors}

The following variables were used as candidate predictors:

1. Year of observation as categorical predictor (seven levels).

2. Easting.

3. Northing.

4. Altitude.

5. Relative altitude; three quantitative predictors, computed as the altitude minus average altitude in a circle with a radius of $100 \mathrm{~m}$, $250 \mathrm{~m}$ and $500 \mathrm{~m}$, respectively.

6. Flooded; three indicators indicating whether location is flooded at a sea-level of 1.90, 2.20 and 2.50 above Dutch Standard Reference Level.

7. Aspect (qualitative predictor with three levels $\mathrm{N}, \mathrm{S}$, and $\mathrm{X}$, defined as follows; $\mathrm{N}$ : aspect between N315E and N45E and slope $>3^{\circ} ; \mathrm{S}$ : aspect between $\mathrm{N} 135 \mathrm{E}$ and $\mathrm{N} 225 \mathrm{E}$ and slope $>3^{\circ}$; X: else).
All quantitative predictors were standardized by subtracting the sample mean and dividing by the sample standard deviation. Note that the predictors altitude, relative altitude and flooded are dynamic, i.e. their values at a given location change over time.

\subsection{Model selection and calibration}

We first selected the best MNL model by stepwise regression in both directions, starting from a full and an empty model and using Akaike's Information Criterion (AIC) as a selection criterion. Year of observation (as a categorical variable, see hereafter) was used as a fixed predictor (always included as a predictor in the model). Then a MMNL model was fitted with the predictors in the selected MNL model as fixed effects and random intercepts. Finally, we tested several submodels by the likelihood ratio test. The smallest submodel that was not significantly worse than the full model was selected.

We used $\mathrm{R}$ package mlogit for fitting MNL and MMNL models (Croissant, 2013). Estimates were obtained by simulation, assuming multivariate normality for the five random intercepts, leading to five variances and ten covariances.

\subsection{Results}

\subsubsection{Calibrated MMNL model}

The predictors in the best MNL model were year (forced predictor), Easting, Northing, altitude flooded(2.20), relative altitude for $100 \mathrm{~m}$ and relative altitude for $250 \mathrm{~m}$. After adding the random
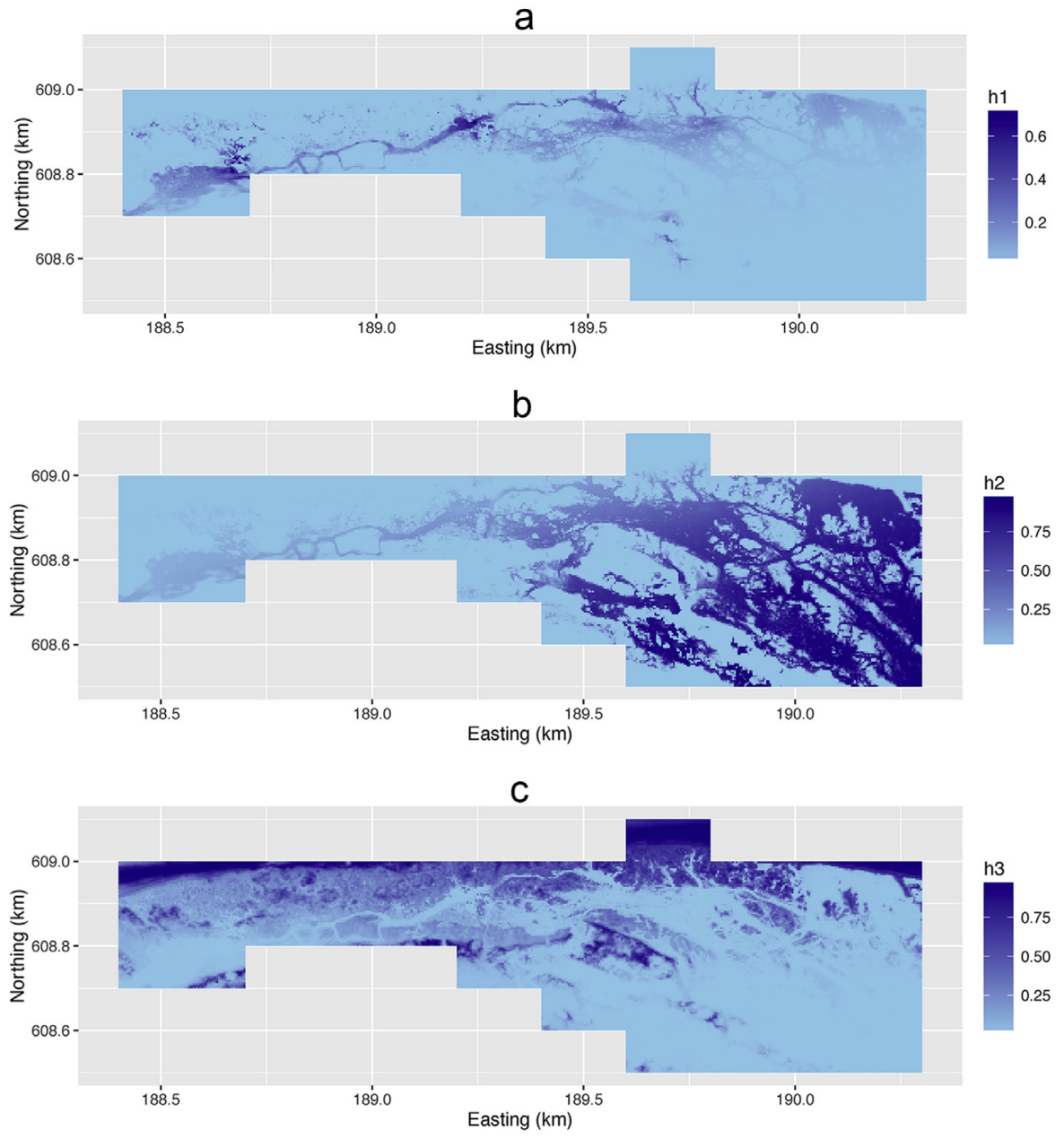

Fig. 4. Predicted probability of occurrence of the habitat type 1 (a), 2 (b), 3 (c), 4 (d), 5 (e) and 6 (f) in 2014. 

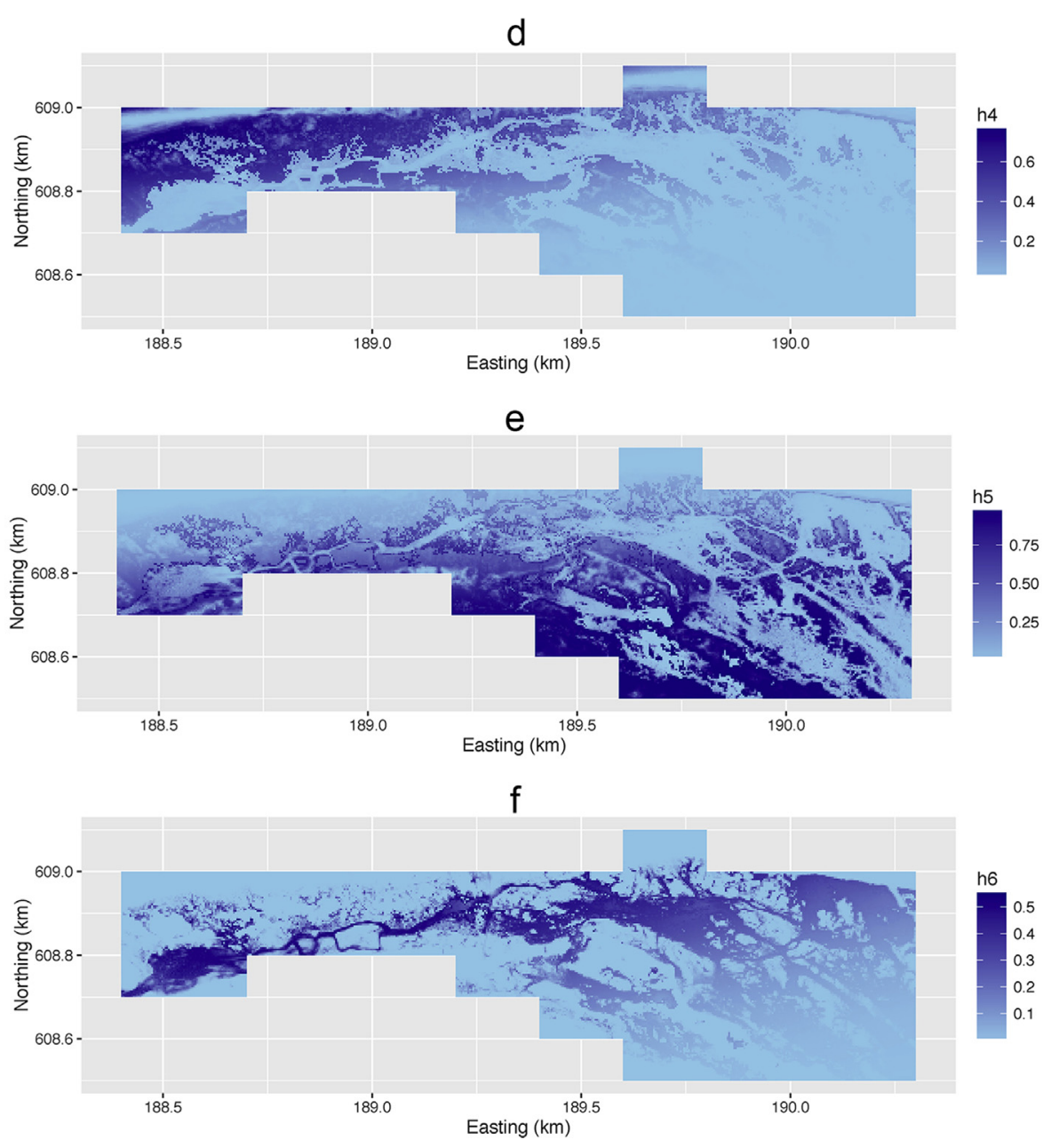

Fig. 4. (Continued).

intercepts, the two relative altitude predictors could be dropped. We also tried to drop year, but this led to a significant decrease of the likelihood. In the selected MMNL model we have one coefficient per alternative habitat type (one habitat type is taken as a reference, see above) for intercept, year (2004), year (2006), year (2008), year (2010), year (2012), year (2014), Easting, Northing, altitude, and flooded(2.20). This gives in total $5 \times 11=55$ regression coefficients. Besides we have 15 coefficients representing the variances and covariances of the random intercepts. This leads to a total number of coefficients of 70 .

Table 2 shows the log likelihood for the model with (MMNL) and without (MNL) random intercepts. The likelihood ratio test showed that the MMNL model was significantly better than the MNL model $\left(\chi^{2}(15)=208.3, p\right.$-value $\left.<0.0001\right)$. McFadden- $R^{2}$ (Menard, 2000) for the MMNL model was substantially larger than for the MNL model.

Fig. 2 shows the estimated regression coefficients for both models. Broadly speaking the coefficients for both models were comparable, but there were also differences, especially for altitude.

Table 2

Summary of multinomial logit model (MNL) and of mixed multinomial logit model (MMNL).

\begin{tabular}{lcc}
\hline & MNL & MMNL \\
\hline Number of coefficients & 55 & 70 \\
Log likelihood & -875.6 & -771.5 \\
McFadden- $R^{2}$ & 0.395 & 0.467 \\
\hline
\end{tabular}

Note, for instance the negative value for the MNL coefficient for altitude for habitat type 2 , whereas this coefficient is positive with the MMNL model. In both models the coefficients for altitude were most extreme, indicating that this predictor had the strongest effect on the probabilities. To highlight the difference between the two models we computed the probabilities of the habitat types as a function of altitude, for year 2014 and flooded(2.20)=TRUE and keeping the other predictors (Easting and Northing) constant at their mean values (Fig. 3). With both models the probabilities for all habitat types change dramatically at an altitude of about

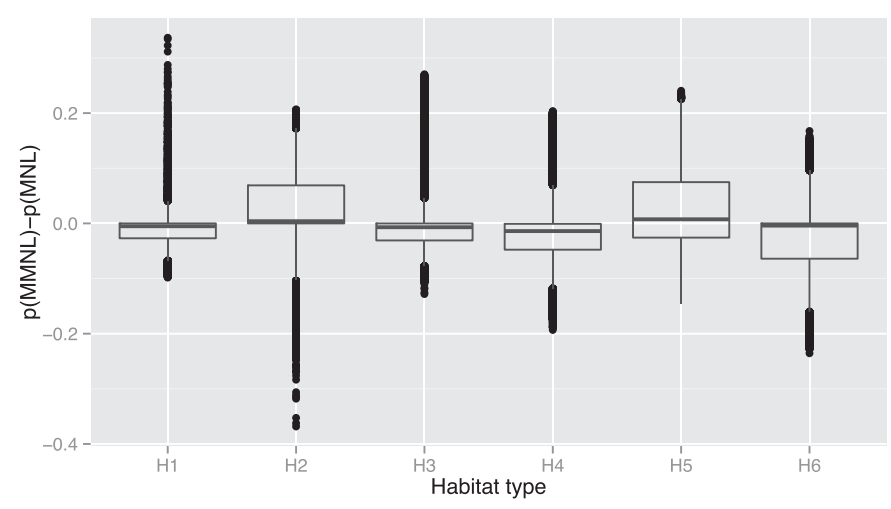

Fig. 5. Differences in probabilities predicted with the MMNL and MNL model for 2014. 
$1.9 \mathrm{~m}$. Below this threshold-altitude the wet habitat types Salicornia and other annuals colonizing mud and sand (1), salt meadow (2) and dune slacks (6) have the highest probabilities. Above this threshold the probabilities of white dunes (3), grey dunes (4) and dunes with Hippophae rhamnoides (5) quickly increased. With a further increase of altitude the probability of grey dunes was more or less constant, whereas that of white dunes increased at the expense of the probability of dunes with Hippophae rhamnoides. The probabilities for habitat types 1 and 2 differed considerably between the two models. The MMNL model predicted much higher probabilities for habitat type 1 . This probability decreased with altitude. With the MNL model the probability of habitat type 1 increased with altitude. From an ecological point of view this is counter-intuitive.
The standard errors of the regression coefficients were largely different between the two models (Fig. 2). The standard errors of the regression coefficients in the MMNL were considerably larger. The small standard errors of the coefficients of the MNL model are not realistic as with this model we do not account for pseudoreplication at the permanent plots.

\subsubsection{Probability maps and habitat type map}

Fig. 4 shows the probabilities for the six habitat types predicted with the MMNL model, for the year 2014. For other years similar maps have been made. These maps were compared with the probability maps as obtained with the MNL model. The differences between the MMNL and MNL maps were small, which was as expected because the differences in the estimated regression
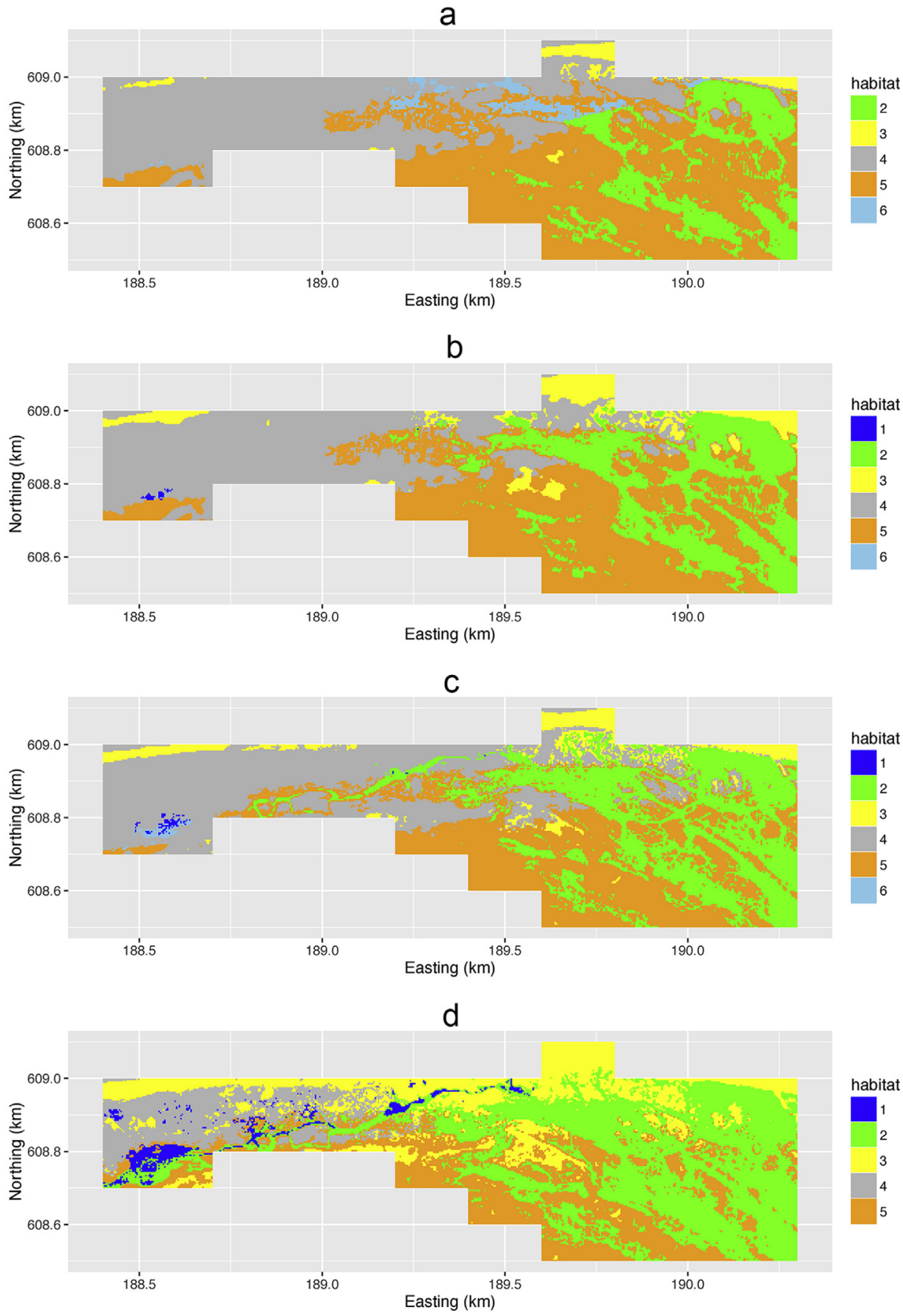

Fig. 6. Predicted habitat types in 2001 (a), 2004 (b), 2006 (c), 2008 (d), 2010 (e), 2012 (f) and 2014 (g). 

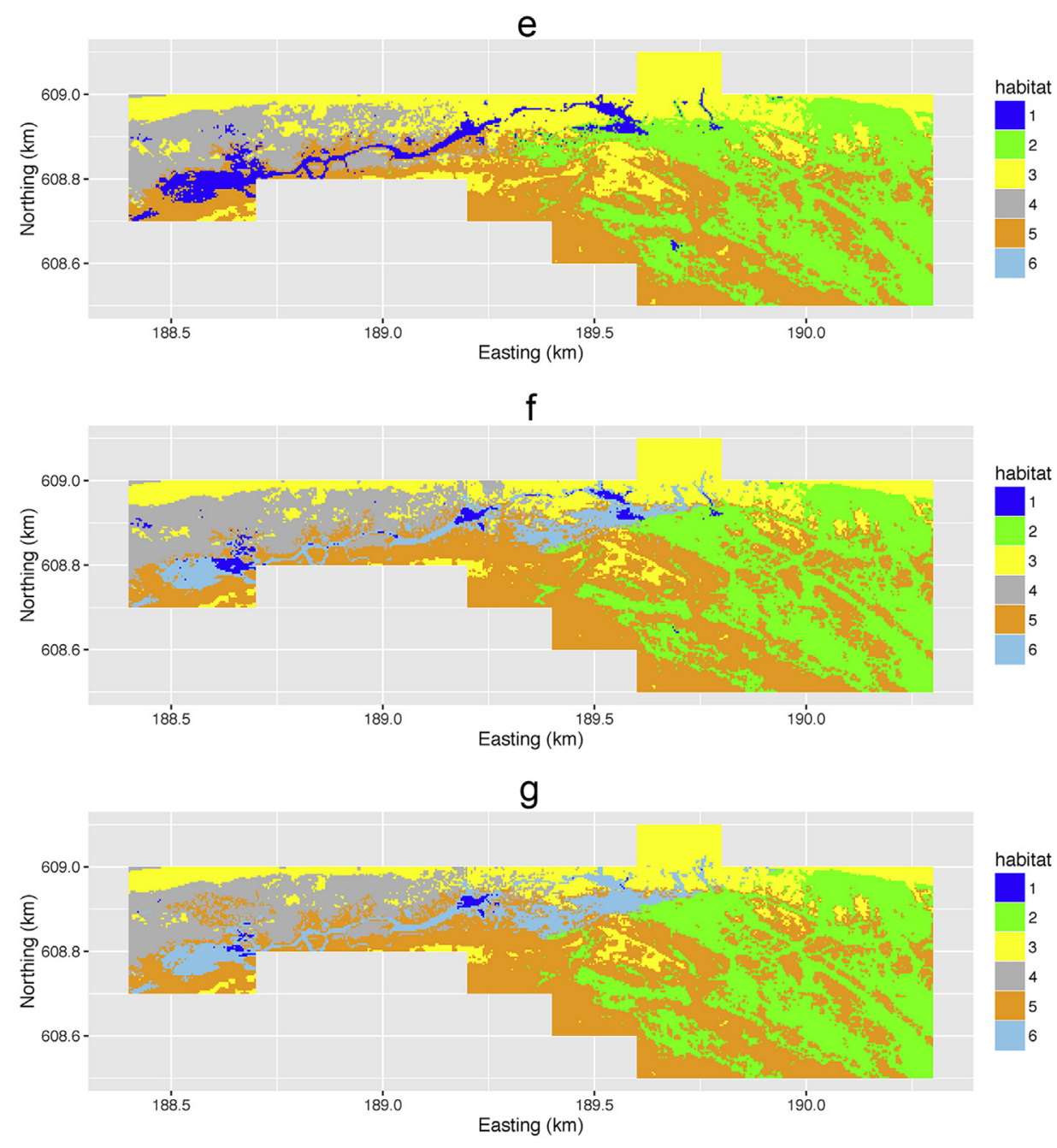

Fig. 6. (Continued).

coefficients were small. Fig. 5 shows boxplots of the difference in probabilities for 2014 as an example.

Finally, Fig. 6 shows the maps with the predicted habitat types in the seven years as obtained with the MMNL model. The habitat type with the largest probability was taken as the predicted habitat type. The MMNL maps and MNL maps with predicted habitats were very similar: for $91-94 \%$ of the nodes the same habitat was predicted.

\subsection{Discussion}

The spatial pattern of habitat types appeared to be highly dynamic. The most important temporal trends that can be seen on the maps are:

- the increase of habitat type 2 in the $\mathrm{E}$ of the area in 2006, followed by a decrease after 2008 ;

- the increase of habitat types 1 and 2 in the $\mathrm{N}$ and $\mathrm{NW}$ of the area after 2004;

- the replacement of type 1 by type 6 in the NW of the area after 2010;

- the general increase of habitat type 3 in the $\mathrm{N}$ of the area.

Broadly speaking, the above-mentioned changes except the last one entail an increase of the wet habitats (salt meadow and dune slacks) at the expense of grey dunes. The most important abiotic drivers for the vegetation changes are probably (1) sea-level rise, (2) soil subsidence, and (3) a restoration project where vegetation and topsoil were removed in the NW of the study area in 2005 (cf. Brus et al., 2014). All these drivers act in the same direction, viz. wetting and salinization. During our 14 year observation period, the most prominent changes took place between 2004 and 2008. This period coincides with the strongest abiotic changes: the restoration project in 2005, and a high storm frequency between 2005 and 2008 (Krol, 2011). The high seawater levels resulting from storms were even increased by soil subsidence that progressively increased over our whole observation period (Ketelaar et al., 2011).

Fig. 6 clearly shows what happened after the restoration project in 2005. Seawater, that during storms enters the area in the SE (at c. $190.3 \mathrm{~W}$ ) and from there flows to the NW, entered the restoration area in the East at c. $189.5 \mathrm{~W} 609.0 \mathrm{~N}$, and formed a gully that extended up to the western edge of the area. First, this gully was filled with salt meadow, but after the high floods in 2005-2008, Salicornia and other annuals colonising mud and sand became the most prominent habitat type. After 2010, when storm frequency decreased, succession took place toward dune slack, although patches of Salicornia, etc. remained. Outside this gully the restoration area was progressively colonised by Hippophae rhamnoides, most notably after 2010 .

The overall decrease of the grey dune Habitat type is probably for the larger part due to the restoration project. In 2001 the restoration area (roughly West of $189.2 \mathrm{~W}$ ) was almost entirely covered by this Habitat type, while after 2006 it was replaced by various other types. Part of the decrease of this type is due to its replacement by white dunes, which happened all over the northern part of the 
study area and not only in the restoration area. This is probably due to the 'dynamic coastal management' regulation that became effective after 1995 (de Jong et al., 2014). Under this regime less intensive measures are taken to prevent the blowing of sand. Note that white dunes not only replaced grey dunes, but also other types such as Dunes with Hippophae rhamnoides in the centre of the study area.

\section{Conclusions}

We conclude that in environmental modeling of categorical variables, dependency of repeated observations at permanent plots can be accounted for by adding random effects to the multinomial logit model, leading to a mixed multinomial logit model. Conditional on the random effects, the repeated observations at a location are assumed independent. In the case study on habitat types the likelihood ratio test showed that the MMNL model with random intercepts was significantly better than the MNL model. The two models differed not so much in the estimated regression coefficients, although there were some differences, but more in the standard errors of the coefficients. The standard errors of the MMNL coefficients were considerably larger, which is as expected, because in the MMNL model pseudo-replication due to dependency of the repeated observations at the permanent plots is accounted for.

In the MMNL model presented in this paper spatial correlation of the random effects is not modeled. Only correlation of the repeated observations at the same location is accounted for by allowing each location to have its own habitat dependent intercept. The observations at different locations are assumed independent. We might expect that when at a given location the random intercept for a given habitat type is strongly positive due to some unobserved covariate, at a nearby location this intercept will also be positive when the unobserved covariate is spatially structured. It would be interesting to see whether extending the model with correlation of the random effects at different locations would improve the model. This can be done as follows. The covariance of a given random effect, for instance the random intercept for habitat type 2 , at two locations is modeled as a function of the distance (and direction) between the two locations. Only authorized functions can be used for this, leading to positive semidefinite covariance matrices (Diggle and Ribeiro, 2007). Examples are exponential, spherical or the Matern functions. Besides, the cross-covariance of two random effects, for instance the random intercepts of habitat types 2 and 3 , at two locations is modeled as a function of the distance (and direction) between the two locations. In the case study with five random intercepts this would result into 15 of these covariance functions. Any linear combination of the five random intercepts should have positive or zero variance. This can be ensured by a linear model of coregionalization, see Webster and Oliver (2007) for a thorough explanation. Such a model would be the multinomial counterpart of the Generalized Linear Spatial Model (GLSM) for binomial data (Diggle and Ribeiro, 2007).

\section{Acknowledgements}

This research is part of the strategic research program KB IV 'Sustainable spatial development of ecosystems, landscapes, seas and regions' which is funded by the Dutch Ministry of Economic Affairs, Agriculture and Innovation, and carried out by Wageningen University Research Centre. We thank our colleagues Gerard Dirkse and Marlies Sanders for their contribution to the monitoring set up and the work in the field, and It Fryske Gea for permission to collect the data in the research area.

\section{References}

Brus, D.J., Slim, P.A., Heidema, A.H., van Dobben, H.F., 2014. Trend monitoring of the areal extent of habitats in a subsiding coastal area by spatial probability sampling. Ecol. Indic. 45, 313-319.

Chen, Z., Kuo, L., 2001. A note on the estimation of the multinomial logit model with random effects. Am. Stat. 55, 89-95.

Cochran, W.G., 1977. Sampling Techniques. Wiley, New York.

Croissant, Y., 2013. mlogit: Multinomial Logit Model. R Package Version 0.2-4. http:// CRAN.R-project.org/package $=$ mlogit.

de Gruijter, J.J., Brus, D.J., Bierkens, M.F.P., Knotters, M., 2006. Sampling for Natural Resource Monitoring. Springer, Berlin.

de Jong, B., Keijsers, J.G.S., Riksen, M.J.P.M., Krol, J., Slim, P.A., 2014. Soft engineering vs. a dynamic approach in coastal dune management: a case study on the North Sea barrier island of Ameland, The Netherlands. J. Coast. Res. 30, 670-684.

de Rooij, M., Schouteden, M., 2012. The mixed effects trend vector model. Multivar. Behav. Res. 47, 635-664.

Diggle, P., Ribeiro Jr., P., 2007. Model-based Geostatistics. Springer.

Duchesne, T., Fortin, D., Courbin, N., 2010. Mixed conditional logistic regression for habitat selection studies. J. Anim. Ecol. 79 (3), 548-555.

EC, 2007. Interpretation Manual of European Union Habitats. European Commission DG Environment, Nature and Biodiversity, Brussels.

Hartzel, J., Agresti, A., Caffo, B., 2001. Multinomial logit random effects models. Stat. Model. 1, 81-102.

Hedeker, D., 2003. A mixed-effects multinomial logistic regression model. Stat. Med. 22, 1433-1446.

Hosmer, D.W., Lemeshow, S., 1989. Applied Logistic Regression. Wiley, New York.

Jain, D., Vilcassim, N., Chintagunta, P., 1994. A random-coefficients logit brandchoice model applied to panel data. J. Bus. Econ. Stat. 12, 317-328.

Ketelaar, G., van der Veen, W., Doornhof, D., 2011. Monitoring effecten van bodemdaling op Ameland-Oost: evaluatie na 23 jaar gaswinning. Dee 1. Ch. Bodemdaling., pp. 8-27 http://www.waddenzee.nl/fileadmin/content/ Bodemdaling/2011/pdf/Rapport_Deel_1_Bodemdaling.pdf.

Krol, J., 2011. Monitoring effecten van bodemdaling op Ameland-Oost: evaluatie na 23 jaar gaswinning. Deel 2. Ch. Monitoring van inundatie in duinvalleien op Oost-Ameland 2001-2011., pp. 169-207 http://www.waddenzee.nl/fileadmin/ content/Bodemdaling/2011/pdf/Rapport Deel 2 duinvallen.pdf.

Lohr, S.L., 1999. Sampling: Design and Analysis. Duxbury Press, Pacific Grove, USA.

Menard, S., 2000. Coefficients of determination for multiple logistic regression analysis. Am. Stat. 54, 17-24.

Quenouille, M.H., 1949. Problems in plane sampling. Ann. Math. Stat. 20, 355-375.

Revelt, D., Train, K., 1998. Mixed logit with repeated choices: households' choices of appliance efficiency level. Rev. Econ. Stat. 80, 647-657.

Särndal, C.E., Swensson, B., Wretman, J., 1992. Model Assisted Survey Sampling. Springer, New York.

Schaminée, J.H.J., Weeda, E.J., Westhoff, V., 1998. De vegetatie van Nederland 4 plantengemeenschappen van de kust en van binnenlandse pioniermilieus. Opulus Press.

Train, K., 2003. Discrete Choice Methods with Simulation. Cambridge University Press, Cambridge.

van Dobben, H., Bobbink, R., Bal, D., van Hinsberg, A., 2014. Overview of critical loads for nitrogen deposition of Natura 2000 habitat types occurring in The Netherlands. Tech. Rep. 2488, Alterra, Wageningen UR, Wageningen, Netherlands.

van Tongeren, O., Gremmen, N., Hennekens, S.M., 2008. Assignment of relevés to pre-defined classes by supervised clustering of plant communities using a new composite index. J. Veg. Sci. 19, 525-536.

Webster, R., Oliver, M.A., 2007. Geostatistics for Environmental Scientists, second ed. Wiley, Chichester. 